\title{
As experiências das Oficiais da Marinha do Brasil no exercício do comando
}

\author{
Vanessa Coelho dos Reis' (iD) 0000-0001-9432-2622 \\ Luciana Patrícia Zucco² (i) 0000-0002-2987-3142 \\ 'Instituto Federal Catarinense, Brusque, SC, Brasil. 88354-300 - \\ falecom@brusque.ifc.edu.br \\ ${ }^{2}$ Universidade Federal de Santa Catarina, Florianópolis, SC, Brasil. \\ 88040-900 -dss@contato.ufsc.br
}

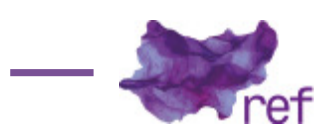

\section{Resumo:}

No presente artigo analisamos o acesso e a constituição da liderança das Oficiais da Marinha do Brasil no cargo de direção. O suporte teórico está ancorado nos estudos feministas. Para a construção e análise dos dados foi utilizada a abordagem metodológica de história oral. As sujeitas da pesquisa são as Oficiais que foram Diretoras de Organizações Militares entre 2002 e 2015. A liderança das entrevistadas evidenciou suas características, desenvolvidas ao longo de suas vidas e potencializadas (ou adquiridas) no exercício do comando, como racionalidade, competência, autoridade e voz de comando, proximidade com o efetivo, saber ouvir, buscar apoio.

Palavras-chove: mulheres nas Forças Armadas; cargo de direção; estudos feministas; história oral.

\section{The Experiences of Brazilian Navy Officers Women in the Exercise of Command} Abstract:

This article analyzes the access and constitution of the leadership of the Brazilian Navy Officers Women in the position of direction. Theoretical support is anchored in feminist studies. For the construction and analysis of the data the methodological approach of oral history was used. The subjects of the research are the Officers who were Directors of Military Organizations between 2002 and 2015. The leadership of the interviewees showed their characteristics, developed throughout their lives and potentialized (or acquired) in the exercise of command, as rationality, competence, authority and voice of command, proximity to the staff, knowing how to listen, seek support.

Keywords: Women in the Armed Forces; Position of direction; Feminist studies; Oral history.

\section{Considerações iniciais}

No artigo em tela analisamos as experiências das Oficiais' da Marinha do Brasil (MB) que ocuparam o cargo de titular ${ }^{2}$ de Organizações Militares (OM). Recorremos à categoria experiência (Joan Wallach SCOT, 1998) para compreender não apenas as vivências, mas, principalmente, o contexto que as fomentaram, como foram produzidas e sua autoprodução para a constituição das identidades 3 (Marcia MORAES, 2002) das Oficiais, na condição de militares dirigentes de OM. Segundo Scott (1998), experiência é um conglomerado de processos que contribui para a compreensão da dinâmica societária e para a produção identitária dos sujeitos.

\footnotetext{
' Nas Forças Armadas, as/os militares estão divididas/divididos em duas categorias: Oficiais ou Graduadas/Graduados (ou Praças). Hierarquicamente, as/os Oficiais estão ordenadas/ordenados em nível acima das Graduadas/dos Graduados. ${ }^{2}$ Titular é a/o militar nomeada/nomeado para comandar ou dirigir uma Organização Militar, ou seja, é a/o comandante ou diretora/diretor da OM.

${ }^{3}$ Compreendemos a identidade como a construção da percepção que a pessoa tem de si mesma, e como outras pessoas a percebem, moldando sua forma de se expressar no mundo.
} 
A construção desta investigação decorre da trajetória e inserção profissional na MB de uma das autoras deste estudo, ao ocupar o posto de Primeiro-Tenente do Quadro Técnico do Corpo Auxiliar. ${ }^{4}$ Esta vivência possibilitou perceber e experienciar situações que evidenciaram a presença de um ethos ${ }^{5}$ (Leonardo BOFF, 2005) masculino que se sobrepunha às mulheres e ao feminino, promovendo hierarquias e acessos diferenciados à $\mathrm{MB}$.

A Marinha integra as Forças Armadas do Brasil, em conjunto com o Exército e a Aeronáutica. Suas protoformas remontam ao século XVI (BRASIL, 1997) e, por isso, a elevam à condição de Força Armada mais antiga do país. A MB possui funções específicas atreladas ao emprego do poder naval $^{6}$ no mar, em faixas litorâneas e em águas fluviais. Com os meios aeronavais e o pessoal habilitado a operá-los, garante operações de defesa do território brasileiro.

As regras e as normas da Marinha se relacionam diretamente com as características de sua missão e sua base constitutiva - a hierarquia e a disciplina. O estrito cumprimento dessas normativas é um componente orgânico da carreira militar.

Historicamente, a MB priorizou o recrutamento de membros do sexo masculino para a composição do seu efetivo. Durante séculos, unicamente os homens formaram as fileiras dessa Força Armada e, consequentemente, contribuíram para sua formação, assim como para as representações do masculino dentro e fora da Instituição. O acesso das mulheres ocorreu somente a partir de 1981, sendo tal fato pioneiro no âmbito das Forças Armadas brasileiras (Maria Rosa LOMBARDI, 2010).

A inserção das mulheres na MB buscou suprir a necessidade de pessoal para executar as funções técnicas e administrativas que eram realizadas pelos homens, possibilitando aos militares serem remanejados para a parte operativa, ou seja, a defesa direta do território (Helena CARREIRAS, 2004; Hermógenes Hiron Marques JÚNIOR, 1982). Logo, a presença das militares nas áreas técnicas e administrativas as excluía do envolvimento no combate e, consequentemente, implicava sua assunção ao cargo de titular apenas em $O M$ de apoio à missão precípua da Instituição.

É nesse contexto, atravessado por um conjunto de símbolos, valores, atitudes e comportamentos masculinizados, que se inserem as mulheres na MB e desenvolvem suas carreiras. Experiências subjetivas e coletivas são particularizadas e se distinguem do "mundo civil", em um processo contínuo de construção de identidades sociais, em consonância com o ser militar (Celso CASTRO, 2004). Para tanto, cursos de formação constituem um dos critérios de ingresso na Instituição e correspondem a uma etapa de preparação à vida militar naval (CASTRO, 2004; JÚNIOR, 1982) para moldar o pensar e o agir. Essa formação tem por objetivo promover a identificação, bem como a pactuação com o espaço e os princípios institucionais, expressa na organização militar, de modo capilar, em seus regulamentos, códigos verbais e gestuais, vestimentas, rotinas, entre outras dinâmicas. Às/aos ingressas/ingressos são apresentadas a arquitetura militar e seus mecanismos disciplinares, que estabelecem relações de poder intrainstitucionais (Michel FOUCAULT, 2009) e naturalizam as formas de submissão às autoridades e aos instrumentos de controle.

Informadas por essa lente de interpretação, analisamos o acesso e a constituição da liderança das Oficiais da MB no cargo de direção. Algumas indagações foram trazidas para a discussão e se impõem como centralidade do estudo: Como as diretoras de OM interpretaram seu percurso profissional na Marinha? O que significou, subjetiva e institucionalmente, mulheres serem diretoras de $\mathrm{OM}$ ? Quais situações de enfrentamento foram experienciadas pelas militares no cargo de titular de OM? Como a rede de características (Linda NICHOLSON, 2000) que possuem e/ou assumem possibilitou o acesso ao cargo de direção?

Segundo Nicholson (2000), a rede de características, concepção cunhada com a proposta de retornar à categoria 'mulher' como dimensão analítica nos anos de 1990, refere-se à interconexão entre diferenças e semelhanças existentes no novo sujeito coletivo 'mulher'. A argumentação da autora rejeita o essencialismo e uma identidade feminina universal. Entretanto, introduz um conteúdo político-social que, atrelado ao dado biológico, unificaria politicamente as mulheres, sendo o sexo um fator estratégico de articulação. Desse modo, recuperamos o conceito de rede de características e a categoria 'mulher', revisitada por Nicholson (2000), para ressaltar as particularidades e os pontos de convergência entre as Oficiais.

Utilizamos a história oral como abordagem metodológica, aplicada ao campo da memória (Silvia SALVATICI, 2005; Alessandro PORTELLI, 1997), a partir da história temática (Verena ALBERTI, 2013; 2004). O suporte teórico do estudo está fundamentado na epistemologia feminista (Sandra HARDING, 2002; Margareth RAGO, 1998). Essa forma de produção de conhecimento assegura "[...] una manera particular de conocer y de producir conocimientos [...]" (Martha Patricia Castañeda SALGADO, 2008, p. 14), bem como características específicas ao debate, a saber: é uma

\footnotetext{
${ }^{4} \mathrm{As} / \mathrm{os}$ Oficiais do Corpo Auxiliar exercem atividades de apoio técnico, gerenciais e administrativas em geral.

${ }^{5}$ Qualifica-se como ethos as características que constituem e organizam um determinado meio social, e que são expressas pelas/pelos sujeitas/sujeitos e pelas instituições inseridas nessa realidade.

${ }^{6}$ O poder naval corresponde ao aparelhamento operativo da Marinha, como navios, submarinos, aeronaves, viaturas e sistemas de armas.
} 
investigação realizada por mulheres, sendo uma das autoras ex-Oficial da MB, logo, a pesquisadora é, simultaneamente, sujeito cognoscente e sujeito cognoscível (SALGADO, 2008); o contexto de pesquisa é um espaço de interação comum; as sujeitas da pesquisa são mulheres; as mulheres entrevistadas 'contam' suas experiências, que conformam o eixo estruturante da narrativa histórica.

É importante destacar que a produção científica sobre a participação das mulheres na MB (LOMBARDI, 2010; LOMBARDI; Cristina BRUSCHINI; Cristiano M. MERCADO, 2009; Mariza Ribas D’Ávila de ALMEIDA, 2008) não prioriza as experiências de gestão baseadas nas narrativas e histórias das sujeitas, ainda mais pelas lentes dos estudos feministas e de gênero. O protagonismo das mulheres é secundarizado diante de uma trajetória consolidada e, por muitos anos, exclusiva aos homens. As vivências das diretoras de OM são singulares e pioneiras no âmbito das Forças Armadas, que se apresentam como espaço paradigmático das lutas pela equidade de gênero.

Para situar a discussão, organizamos o texto em três seções: percurso metodológico, incluindo as características das protagonistas, na condição de diretoras de OM; principais resultados, contemplando a análise das histórias das diretoras, suas narrativas e experiências no cargo de direção; considerações finais, onde retomamos as perguntas norteadoras para tecer algumas reflexões sobre as histórias relatadas.

\section{Percurso metodológico}

A história oral constituiu o desenho metodológico do estudo, desde a definição das sujeitas até o processo de coleta dos dados e arquivamento das entrevistas. A narrativa das Oficiais foi a principal fonte da pesquisa, sendo informada pela memória (SALVATICI, 2005). Esta é tecida como uma rede, com fatos constituídos pelo sujeito e pela coletividade. A inserção e participação dos sujeitos na tessitura social constroem e moldam suas experiências (SCOTT, 1998).

A opção acadêmica por essa estratégia metodológica confirma a autoridade da narrativa e a importância de ser protagonizada pelas mulheres. Elas tiveram a liberdade para 'contar' suas experiências em limites localizáveis no tempo, estabelecidos pelas indicações conceituais da história temática (ALBERTI, 2013; 2004), que é uma das formas pela qual a história oral pode ser perspectivada. Nesse sentido, a história temática foi empregada para orientar a definição do assunto, do evento analisado e da delimitação temporal específica, bem como subsidiar a construção do corpus e do roteiro da entrevista. Com isso, possibilitou a imersão nas experiências de cada entrevistada, a partir de um fragmento de suas histórias profissionais, com destaque à condição de gestoras, projetando suas ações na história geral da MB.

As sujeitas da pesquisa foram as Oficiais titulares de OM em exercício no cargo de direção entre 2002 e 2015. Em janeiro de 2016, iniciamos o contato com as possíveis entrevistadas, via email, a partir de uma listagem encaminhada pela Diretoria do Pessoal Militar da Marinha, que continha os dados de 16 diretoras. No e-mail, explicamos o motivo do contato, ressaltando a importância da pesquisa, a forma de coleta de dados e a garantia de sigilo das informações que não pudessem ser publicizadas. Sem um retorno, o próximo passo foi o contato telefônico, com o aceite de três Oficiais para participarem do estudo - Capitã de Fragata (CF) Wilma Tavares Barreto, Capitã de Mar e Guerra (CMG) Vera Lúcia de Gaia Campos e Capitã de Mar e Guerra (CMG) Gelza de Moura Barbosa.

As entrevistas foram realizadas no segundo semestre de 2016. O encontro com a CMG Vera ocorreu em sua residência, na cidade do Rio de Janeiro/RJ, em duas sessões de entrevista. Com a CF Wilma, a entrevista ocorreu no Shopping RIOMAR, na cidade de Recife/PE. A última entrevista foi realizada com a CMG Gelza, em seu gabinete de diretora do Centro de Manutenção de Sistemas da Marinha (CMS), OM localizada no Rio de Janeiro/RJ. Inicialmente, todas tomaram ciência da carta de cessão de direitos, documento que permite o uso de suas narrativas e a publicização dos resultados do estudo, sendo assinada pelas Oficiais. Do mesmo modo, autorizaram a utilização do gravador de voz e do diário de campo para fins de registro e anotações, bem como o uso de seus nomes civis.

Após a coleta dos dados, iniciamos a transcrição das gravações. O material escrito e sonoro foi enviado às Oficiais para que pudessem identificar trechos não compreendidos e alterar o texto, inclusive em relação à pontuação. Na sequência da devolução do material, continuamos com a organização dos dados, com base nas indicações de Lucília de Almeida Neves Delgado (2010). A autora sugere três ações para a discussão dos dados: a análise de conteúdo, na modalidade temática; uma análise mais profunda e específica a partir dos temas construídos; o agrupamento das entrevistas, de modo que cada uma delas se configure em unidade de análise individual e coletiva, possibilitando extrair sua singularidade e realizar comparações entre elas. Assim, cada história foi considerada individualmente para que a especificidade das trajetórias fosse projetada e suas experiências situadas em um contexto compartilhado. Quando possível, evidenciamos os nexos entre as histórias, explicitando particularidades, similaridades e diferenças, apresentadas a partir da caracterização das entrevistadas e de suas carreiras profissionais na MB. 


\section{Caracterização das sujeitas da pesquisa}

A prerrogativa de comandar ou dirigir uma OM é exclusiva das/dos Oficiais. Em relação às mulheres, de 2002 - ano em que a primeira Oficial assumiu a titularidade de uma OM - a 2015, 16 mulheres militares assumiram o cargo de diretoras. Estas compõem o círculo de Oficiais Superiores ou de Oficiais-generais, ocupando os postos mais elevados da hierarquia militar naval. A seguir, discorremos sobre seus perfis.

A CF Wilma Tavares Barreto nasceu no dia 30 de dezembro de 1954, no estado da Guanabara, atual cidade do Rio de Janeiro. É mãe de um filho e de uma filha. Ao ser indagada sobre sua cor de pele, não a especificou e declarou como a sociedade a denominaria: "Sei que sou considerada branca ou morena [...]". De modo reativo, sugere que a cor da sua pele é um atributo físico que não altera sua condição de ser humano, como expressou na seguinte afirmação: "Eu acho que eu me sinto bem, acho que eu navego bem nesse mundo tão conturbado que nós temos hoje em dia. Eu me considero um ser humano estável. Entendeu?" (CF Wilma, 2016 [grifo nosso]). Em sua narrativa, chamou a atenção para a diversidade racial, para o preconceito, e expôs alguns elementos que remetem à colonização do Brasil à época da escravatura e ao padrão de beleza veiculado às mulheres:

Eu tenho a minha tataravó. Era uma negra, escrava. A minha bisavó nasceu no Ventre Livre. Era uma mulata. Já tinha o cabelo liso porque o pai dela era português. [...], mas o preconceito está na cabeça, não está na palavra. [...] adoro os meus cabelos cacheados, me enrosco, não aliso, não faço nada, me sinto muito bem (CF Wilma, 2016).

É médica cardiologista. Ao ser nomeada diretora, encontrava-se separada. Ingressou na Marinha em 1981, integrando a primeira turma de mulheres. Em 2002, tornou-se a primeira Oficial a ser titular de uma OM, em um contexto de direção interina no Hospital Naval de Recife (HNRe). Antes de ser diretora, foi chefe do Departamento de Saúde e vice-diretora. Permaneceu no comando até o final daquele ano, sendo, posteriormente, transferida para a reserva remunerada, em 2004.

A CMG Vera Lúcia de Gaia Campos nasceu no dia 20 de novembro de 1957, na cidade do Rio de Janeiro/RJ, onde mora com o marido, dois filhos e uma filha. Assim como a CF Wilma, apresentou indefinição a respeito da cor de sua pele, autodenominando-se branca e morena: "Eu sou branca. Sou morena, mas branca". É psicóloga de formação. Também ingressou na MB em 1981. Foi diretora do Serviço de Seleção do Pessoal da Marinha (SSPM) entre 2006 e 2008, e transferida para a reserva remunerada após o término de seu comando.

A CMG Gelza de Moura Barbosa nasceu no dia 26 de maio de 1966, na cidade do Rio de Janeiro/RJ, e ali reside com suas duas filhas e filho. Quando questionada sobre a cor de sua pele, a resposta foi uma pergunta retórica: "A minha cor de pele ou cor de alma?". Expressou criticamente que não tem uma cor, e concluiu que é um arco-íris, manifestando resistência aos 'rótulos' raciais: "Sempre quando alguém me pergunta, eu coloco lá: 'não quero declarar', apesar de na minha certidão de nascimento estar escrito branca".

De modo geral, as narrativas das Oficiais revelaram a existência de uma sociedade racialmente diversa, na qual a diferença racial gera desigualdade. Em nenhum outro momento da entrevista recuperaram a crítica ao mito da democracia racial e ao projeto de branqueamento da população (Silvia Elaine Santos de CASTRO, 2013; Sueli CARNEIRO, 2011), subliminar em suas respostas frente à indagação da autodefinição da cor.

No momento da entrevista, a CMG Gelza de Moura Barbosa se encontrava divorciada. Formou-se em engenharia elétrica e ingressou na MB em 1990. Foi a primeira diretora do Centro de Manutenção de Sistemas da Marinha (CMS), no período de 2015 a 2017 , e, com isso, marcou outro momento para as mulheres na Marinha, como primeira titular de uma OM da área tecnológica e não assistencial. Se as demais inauguraram a história das mulheres na MB, em 1981 e 2002, a CMG Gelza avança em um espaço ocupacional destinado exclusivamente aos homens (LOMBARDI, 2010) e autorizado pela racionalidade masculina (Fabíola ROHDEN, 2001). A figura de uma mulher no comando do CMS rompeu com a tradição de gestões androcêntricas na MB, que, de certo modo, reproduzia a socialização binária de gênero: nas OM assistenciais, a direção era habilitada às mulheres; e nas OM tecnológicas e de atividades-fim, aos homens.

Suas histórias apresentam um movimento contínuo de adequação e correspondência às exigências institucionais, assim como de alteração dos espaços e relações profissionais, em um campo demarcado por regras e por autonomia limitada (Pierre BOURDIEU, 2004). Ou seja, as Oficiais desencadearam uma desconstrução das atribuições, lugares e predicados do feminino, e promoveram suas próprias referências para o exercício profissional e de poder, por vezes, parametrizadas pelos padrões hegemônicos institucionais. Tal dinâmica também foi registrada pela pesquisa de Lucas Bueno de Freitas e Nanci Stancki da Luz (2017), ao mapearem o estado da arte dos estudos sobre gênero, ciência e tecnologia no Brasil.

Ademais, a presença das mulheres na MB evidencia um processo mais amplo e histórico, que nos reporta às contribuições das lutas políticas dos movimentos feministas. Em âmbito societário, 
as mulheres questionaram as opressões femininas e, simultaneamente, interferiram nas referências masculinas enraizadas nas instituições sociais. Apesar do legado, dentre outros, do feminismo branco de classe média (Djamila RIBEIRO, 2017; 2016; Maria Gabriela HITA, 2002), as Oficiais entrevistadas estabeleceram um distanciamento e negaram qualquer identificação com as posições feministas: "Ah, você é feminista? Não, porque a feminista é aquela que, às vezes, se coloca contra o homem" (CF Wilma, 2016).

Ainda que partilhassem das condições de opressão do sujeito 'mulher' (Adriana PISCITELLI, 2004), todas as Oficiais tiveram acesso à faculdade e a cursos universitários com prestígio social; possuem pós-graduação, incluindo doutorado, no caso específico da CMG Gelza, e suas qualificações estão diretamente relacionadas à especificidade do trabalho desempenhado na MB. É possível afirmar que as Oficiais conquistaram socialmente um lugar de privilégio, inclusive no âmbito da Marinha, ao comporem o restrito grupo de diretoras de OM. Suas experiências individuais e coletivas não correspondiam às vivências de outros grupos de mulheres, em que a subalternidade é determinada por fatores simultâneos de exclusão e opressão, como a cor da pele, a classe social e o gênero (Patricia Hill COLLINS, 2017; RIBEIRO, 2017; 2016).

\section{O acesso ao cargo de direção}

O processo de escolha das/dos Oficiais nomeadas/nomeados para assumir a titularidade de OM não é o objeto de pesquisa deste estudo. No entanto, o assunto se projetou nas narrativas. Por isso, apresentamos brevemente os procedimentos para a seleção das/dos titulares.

A CF Wilma assumiu a direção do HNRe com 48 anos de idade, e ocupava o posto de Capitã de Fragata. Sua assunção foi atípica, provisória e não planejada pela MB, pois exerceu o cargo interinamente.

O processo foi o seguinte: ele [o diretor do HNRe] tinha que sair porque ele precisava ir embora. [...]. E não tinha ninguém. [...]. Aí, o Almirante Saboia, que é uma pessoa que eu prezo de montão, que era o Comandante do $3^{\circ}$ Distrito Naval, disse: "Ué? A Wilma fica". E aquele 'Hã? Hã? Hã?'. Mas o Almirante Saboia também é um homem à frente do seu tempo. Ele disse: "Qual é o problema? Vai movimentar alguém do Rio para quê? Se ela está aqui, ela conhece o hospital inteiro. Ela é a vice. [...]. A Wilma fica". E a Wilma ficou (CF Wilma, 2016).

A utilização da expressão 'Hã? Hã? Hã?' foi um indicativo do sobressalto da tripulação’ do HNRe pelo fato de ser uma mulher a assumir a direção, como sugerido no seguinte trecho: "[...] o Almirante Saboia também é um homem à frente do seu tempo". Nesse momento, a funcionalidade e a logística institucionais foram privilegiadas, sobrepondo-se à cultura de gestão masculina. $O$ ineditismo da indicação e a 'alteração' dos trâmites para o exercício do comando atravessaram outros momentos de sua fala, quase sempre de modo subliminar, a exemplo da ciência de sua nomeação.

Eram dois sentimentos. Primeiro, o sentimento de medo mesmo: "Meu Deus! Como é que eu vou fazer?". Uma coisa é você ser vice ou ser chefe do Departamento de Saúde. Outra coisa é você ter uma responsabilidade de uma OM. A primeira mulher, com todo mundo, assim, olhando para você, porque todo mundo ia olhar. A primeira foi essa. Depois eu me senti orgulhosa pela confiança que o meu Comandante tinha em mim (CF Wilma, 2016).

Ao narrar sua assunção ao cargo de direção, a CF Wilma ressaltou, enfaticamente, a manutenção dos ritos institucionais, historicamente realizados para os titulares de OM: "Teve passagem de comando, o broche de comando. Tudo. Foi tudo com portaria. Não podia ser... Com tudo o que tem direito. Eu fui a diretora interina, mas fui a diretora [...]". Sua gestão trouxe 'desconfortos', não apresentados explicitamente, conforme indica esta passagem a respeito do término de seu comando: "Aí quando chegou no final de dois mil e dois, houve necessidade de colocar outra pessoa, entendeu? Então, os ânimos se acalmaram". A maior parte de sua história foi narrada de forma firme e incisiva. Mas, nessa parte, expôs lentamente e com um tom de voz menos intenso 'os ânimos se acalmaram', expressando o alívio da tripulação com o encerramento de sua curta direção.

A CMG Vera tinha 48 anos quando assumiu a direção do SSPM, em 2006. Ela era Capitã de Mar e Guerra, posto exigido para o comando daquela OM. Mencionou que, nesse mesmo ano, outras quatro Oficiais também assumiram a titularidade de OM. Todas eram médicas, exceto a CMG Vera, que era psicóloga. Ela tinha ciência de que o bom desempenho de sua gestão proporcionaria oportunidades para que outras Oficiais e psicólogas/psicólogos militares pudessem ser titulares, uma vez que foi a primeira diretora que não era médica. O pioneirismo de sua gestão está relacionado à possibilidade de ampliação do exercício do comando por mulheres com outras formações profissionais, para além da medicina, demarcando um processo contínuo de conquistas no âmbito societário e endógeno à MB.

Quando referenciou que compôs o primeiro grupo de diretoras, a CMG Vera se reportou aos trâmites institucionais tradicionalmente seguidos para a designação de titulares, salientando que

\footnotetext{
${ }^{7}$ Tripulação é a designação do conjunto das/dos militares que servem em uma OM da Marinha.
} 
a nomeação para o cargo de direção é uma atribuição privativa do Comandante da Marinha. Destacou os requisitos levados em consideração no processo de escolha das/dos titulares, como as avaliações, desempenho e o posto, ou a antiguidade ${ }^{8}$ das/dos Oficiais.

Uma dúvida que levamos à CMG Vera foi a respeito da divulgação da concorrência ao cargo de titular. Segundo ela, a/o Oficial não recebe nenhum aviso de que está participando de uma seleção para assumir a direção/comando de uma OM. Por isso, ao ser informada de que seria a titular do SSPM, seus sentimentos foram de orgulho e realização, uma vez que construiu sua carreira tendo como objetivo tornar-se diretora daquela OM.

Ah, foi muito orgulho, porque isso era uma coisa que eu almejava. Inclusive porque a Marinha é um ... as Forças Armadas são, muito assim, tradicionais ... Você vai fazer ... é tijolinho. Bota um tijolinho. Bota outro tijolinho. Bota outro tijolinho. Então, eu sabia que dependia do sucesso da minha direção em abrir para outras pessoas, não só para mulheres, como também para psicólogos (CMG Vera, 2016).

A afirmação de que as Forças Armadas são espaços tradicionais manifesta que a CMG Vera compreendia a cultura e as regras institucionais, bem como demonstra a sua aquiescência às mesmas.

A CMG Gelza, igualmente, tinha 48 anos de idade e se encontrava no posto de Capitã de Mar e Guerra quando assumiu o comando do CMS. Chama atenção o fato de as três sujeitas da pesquisa estarem com 48 anos no momento da assunção ao cargo de direção. Este dado aponta o tempo exigido para que as Oficiais da MB possam ser nomeadas diretoras, que corresponde, em média, há 25 anos de trajetória profissional. Isto se deve, basicamente, à restrição de ingresso das mulheres em determinados estabelecimentos de ensino militar naval para a formação de Oficiais, que viabilize o acesso à titularidade em qualquer $\mathrm{OM}$, inclusive nos meios operativos.

Declarou que não esperava a nomeação, uma vez que não há divulgação para as/os Oficiais de sua concorrência ao cargo de titular. No entanto, de maneira informal, soube que era uma candidata, pois recebeu o telefonema do engenheiro mais antigo da Marinha que a questionou se gostaria de ser diretora, caso fosse indicada. Sua reação, ao ser confirmada a designação, foi de surpresa e gratidão pela confiança depositada em sua capacidade, embora tenha ciência de que a trajetória exitosa que construiu na Instituição propiciou o acesso à direção.

Eu não imaginava que eu fosse ser designada para ser diretora aqui. Não é a gente que pede para ser diretor. A Marinha que escolhe. Então, eu nem sei como isso se passou. O que eu sei é que tenho bastante experiência acumulada nessa área. E eu sempre trabalhei sem pensar que um dia eu seria diretora. Eu nunca pensei assim: "Ah, vou fazer bem feito para poder ser diretora". Então, eu fazia o meu trabalho do jeito que eu gosto de fazer sempre. [...] na hora de escolher um diretor para ser diretor aqui, a Marinha tinha algumas opções de Capitães de Mar e Guerra engenheiros. E a Marinha viu as opções disponíveis e me escolheu por ser a mais experiente e a mais apropriada para o cargo (CMG Gelza, 2016 [grifo nosso]).

O sentido dado à assunção ao cargo é de competência: "A mais experiente e a mais apropriada para o cargo". Competência, racionalidade, eficácia e eficiência são predicados esperados para o exercício da gestão e atribuídos à natureza masculina (Tânia Maria FONTENELEMOURÃO, 2006; Maria da Conceição de Oliveira Carvalho NOGUEIRA, 2006). A expressão de admiração e a utilização do termo 'diretor' demonstraram que a tendência histórica das indicações à direção conjugava 'sexo' e 'bom desempenho profissional'. Contudo, a CMG Gelza foi enfática ao afirmar que o dado biológico não é um elemento levado em consideração pelos Oficiais incumbidos da escolha das/dos titulares: "A Marinha não coloca nos postos de comando pessoas ineficientes só porque são homens ou só porque são mulheres. Ela coloca porque são competentes".

A surpresa e a gratidão com a indicação ao cargo de direção pelas entrevistadas evidenciam que, além de atenderem aos requisitos técnicos e às qualidades esperadas à gestão, teriam uma exigência a mais: provarem que, mesmo sendo mulheres, eram capazes de ascender ao comando (FREITAS; LUZ, 2017; FONTENELE-MOURÃO, 2006).

\section{O exercício da direção}

O relato das diretoras apresentou as atribuições inerentes ao exercício de qualquer cargo de chefia. Porém, também revelou peculiaridades na maneira de exercer o comando e de seu modus operandi. Dentre os aspectos mencionados, a CF Wilma pontuou que a posição hierárquica ocupada pela/pelo diretora/diretor requer um afastamento da convivência com a tripulação.

Olha, a posição de comando é uma posição muito solitária, muito solitária. Porque, quando $C D S$ [chefe do Departamento de Saúde] e quando vice [vice-diretora], [...] eu tinha um corpo a corpo muito estreito com a minha tripulação, tanto de civis como de militares, o que você não pode ter como diretora [...] (CF Wilma, 2016).

\footnotetext{
${ }^{8}$ Refere-se à precedência das/dos Oficiais que ocupam o mesmo posto na hierarquia militar.
} 
A repetição do termo 'muito solitária' enfatiza essa característica, construída institucionalmente e que reforça as relações e os dispositivos de poder (FOUCAULT, 2009) acionados no comando de uma OM. A estrutura hierárquica e todos os seus elementos simbólicos, componentes basilares de espaços institucionais fechados, justificariam o distanciamento da/do titular como uma necessidade intrínseca ao cargo. Na cultura da $\mathrm{MB}$, ser diretora/diretor de $\mathrm{OM}$ exigiria, continuamente, tomada de decisão; portanto, posições objetivas e isentas dos possíveis afetos mobilizados pela proximidade com o efetivo, demarcando lugares e poderes distintos.

É interessante observar que a CF Wilma, ao relatar sua compreensão sobre o lugar do comando, discorreu a respeito desta cultura no âmbito da $\mathrm{MB}$ e fez um contraponto à sua gestão. Expôs suas experiências como parte da tripulação, enquanto vice-diretora, e como titular, na condição de diretora, instituindo outra forma de exercer o poder e inovando a gestão.

\begin{abstract}
Até porque eu não era uma diretora que ficava sentada. Primeiro porque não é da minha personalidade, que eu sou uma pessoa agitada. Segundo, porque eu vinha de uma posição, vamos dizer entre aspas, de vice [vice-diretora], que eu levantava e passeava. Então, eu passeava pelo hospital como diretora. Entrava nos mesmos lugares que eu entrava como vice, entendeu? Entrava como diretora para conversar: "Como é que está?". la ver os ranchos, entendeu? la ver a cozinha. la ver os alojamentos. Está bom, não está bom, entendeu? Então, esse tipo de coisa eu continuei fazendo. Então, vamos dizer... apesar de às vezes eu sentir aquele temor que a pessoa... "É o diretor, entendeu? É a diretora". Mas eu não deixei de estar presente na vida deles. Não fiquei sentada lá dentro. E, geralmente, eu almoçava, pelo menos duas ou três vezes por semana, com algumas pessoas que eu mandava convidar. Desde médico civil a médico militar a funcionários civis. Eu chamava para almoçar na câmara comigo, para conversar (CF Wilma, 2016).
\end{abstract}

A regularidade em convidar pessoas para almoçar em seu gabinete é sugestiva da tendência empregada em sua gestão, uma vez que estabeleceu uma forma de liderança alternativa aos moldes disseminados como naturais ao poder masculino. A manutenção de um relacionamento próximo às/aos subordinadas/subordinados indicava uma ação estratégica e de controle no exercício do seu comando, sem o emprego da coação. Logo, essa modalidade instrumental do uso do poder administrava as possíveis resistências à estrutura estatuída (FOUCAULT, 2009; 2004), em consonância com as qualidades da liderança militar pelo exemplo (CASTRO, 2004), e sem se contrapor à dinâmica institucional.

Para a CF Wilma, outras pessoas a percebiam como autoritária: "[...] uma vez, um colega meu disse assim: 'Wilma, você é autoritária'. Eu disse: 'defina autoritária?'”. Destacou que não se reconhece como autoritária ao fazer a diferenciação com o autoritarismo: "[...] a diferença é que eu tenho autoridade. Autoridade é diferente". Concluiu que a autoridade é uma característica do ato de comandar e fazia uso dela no exercício do seu cargo. A capacidade de agregar e o bom senso também foram apontados pela CF Wilma como qualidades que possuía: "Eu acho também que, dentro da linha de comando, consegui ser agregadora. Eu consegui conciliar as pessoas [...]. Eu tenho bom senso. Eu acho que tenho muito bom senso". A ação de conciliar as pessoas fez referência, novamente, à proximidade que mantinha com as/os subordinadas/subordinados, estabelecendo uma gestão relacional.

Por sua vez, com base no desempenho como diretora, a tripulação, ou melhor, parte dela, reconheceu o comando e a autoridade da CF Wilma: "Eu acho que a maioria não se chocou, nem ficou muito revoltada, não. Os que tinham que ficar revoltados, iam ficar revoltados, a gente já sabe. Mas a maioria aceitou bem".

Em relação à tomada de decisão, buscava, quando necessária, a opinião da tripulação, sendo sempre sua a deliberação final. Afirmou que as decisões da/do diretora/diretor devem suplantar o seu posicionamento pessoal, caso este não seja o mais adequado.

A aplicação de medidas disciplinares, como prender ou denunciar uma/um militar, era utilizada pela CF Wilma, porém como um último recurso, principalmente quando afetava negativamente o convívio da tripulação.

Em sua gestão, não manteve o cargo de vice-direção, que foi ocupado por ela no comando anterior. Desta forma, hierarquicamente abaixo da direção estavam, no mesmo nível, as chefias do Departamento de Administração e do Departamento de Saúde. Essas chefias, igualmente, eram ocupadas por mulheres. Neste sentido, o comando do HNRe era formado por mulheres Oficiais: "Na minha direção foi o triunvirato. Eram as meninas poderosas. Era eu de diretora, Comandante Elizabete de chefe do Departamento de Administração e Comandante Lúcia, chefe do Departamento de Saúde".

Nesse trecho, a fala da CF Wilma foi pronunciada enfaticamente para destacar a formação do comando, 'o triunvirato', que se refere ao exercício do poder administrativo e/ou político por três pessoas. Um exemplo notável de triunvirato são os que ocorreram em Roma antes de Cristo. Os homens que fizeram parte daquela união política (Júlio César; Pompeu, o Grande; Marco Licínio Crasso $-1^{\circ}$ triunvirato. Marco Antônio; Otaviano; Lépido $-2^{\circ}$ triunvirato) foram imortalizados na 
História e, consequentemente, na memória da sociedade, pelas ações que realizaram. A partir desses fatos históricos, questionamos qual a repercussão na MB do primeiro comando composto por mulheres? A história delas é conhecida na Instituição em que serviram? Existe o reconhecimento da MB pelo espaço que ocuparam de forma pioneira?

A narrativa da CF Wilma projetou as mulheres, reforçada pela expressão 'meninas poderosas', 9 que nomeava as Oficiais que compunham, em conjunto com ela, a direção do HNRe. A denominação 'meninas poderosas', utilizada pela tripulação, foi considerada pela CF Wilma como um reconhecimento do trabalho realizado pelo triunvirato de mulheres e não uma dificuldade pelo fato de serem mulheres em cargo de comando: "Lógico que isso a gente soube depois. Mas eu não tenho nada contra. Acho ótimo! Acho até que foi elogioso".

A respeito da caracterização das mulheres que ocupam posições de poder, Nogueira (2006) afirma que a opinião pública supervaloriza tais mulheres, especialmente ao utilizar a palavra 'super' como um prefixo, por exemplo, 'supermulher'. Elas teriam um poder, uma resistência e predicados, inerentes ou obtidos, que as distinguem das 'mulheres comuns'. Nesta concepção, reafirmam-se os 'lugares sociais' designados aos gêneros, no caso da MB, aos sexos. Para ser 'super', ou a mulher é capaz de articular com equilíbrio as atribuições do feminino e do masculino, ou ela abandona as características da 'natureza feminina' para assumir os atributos masculinos (FREITAS; LUZ, 2017). Posto isto, de acordo com a opinião pública, as mulheres não podem assumir a liderança sendo simplesmente mulheres.

O pioneirismo da gestão da CF Wilma representou desafios, relacionados à composição de sua equipe diretiva e às expectativas de militares que compunham diferentes níveis hierárquicos, abrangendo tanto a tripulação quanto o alto comando da MB.

Quando o Comandante de Operações Navais (CON) foi fazer a visita lá, estávamos nós lá, o grupo feminino. Então, foi a primeira vez que você teve aquele triunvirato. Foi toda uma quebra de protocolo. É, menina, não foi fácil, não. Não foi fácil, não. Você não tem ideia de como não foi fácil (CF Wilma, 2016 [grifo nosso]).

O Comando de Operações Navais (ComOpNav) é um órgão de direção setorial subordinado diretamente ao Comandante da Marinha, e sob seu comando está grande parte dos meios operativos da MB. O HNRe possui uma subordinação hierárquica ao ComOpNav. Por isso, a visita do Comandante de Operações Navais era importante, por ser uma grande autoridade. A 'quebra de protocolo' se refere ao fato de que, pela primeira vez na História da MB, três mulheres Oficiais, que dirigiam uma $O M$, recepcionaram um Oficial-general do mais alto posto da hierarquia militar naval. A tripla repetição da expressão 'não foi fácil', verbalizada de forma espirituosa e com um sentimento de pesar, estava associada aos questionamentos dirigidos às Oficiais que se encontravam no comando.

Nesse contexto, negou qualquer prática discriminatória, voltada à sua gestão, por parte da tripulação do HNRe, assim como do Comando do $3^{\circ}$ Distrito Naval. Contudo, em sua narrativa, relacionou as desigualdades que as mulheres enfrentaram no comando como oriundas da diferença sexual e, simultaneamente, mas de modo subliminar, compreendia essas diferenças como construções sociais. Reconhecia as referências biológicas como possibilidade de poder para ambos os sexos, mas nunca como geradoras de desigualdades.

Porque existe uma tendência de minimizar a capacidade feminina de conseguir se dar bem em postos de comando, em postos de autoridade, como se a autoridade e o comando estivessem ligados ao fato de ser masculino. Existe o comando e a autoridade masculina e existe a maneira de comandar e de ter autoridade da mulher, que são diferentes, pela própria característica humana de cada um. O homem é diferente da mulher. Então, nem a mulher precisa se tornar um homem para ser uma boa mulher de negócios [...] ela não tem que se masculinizar. Ela tem que descobrir dentro da força feminina dela a sua capacidade de ter autoridade e de ter comando (CF Wilma, 2016).

A partir dos atributos e dos comportamentos designados e estabelecidos socialmente à mulher, como sensibilidade, maleabilidade e acolhimento, explicou seu entendimento sobre a autoridade feminina, ao expor a capacidade de agregar e de ouvir as/os subordinadas/ subordinados. Porém, sinalizou que tais características não excluem as posturas firmes e duras. Assim, a autoridade da mulher contemplaria todos esses predicados. Em contraposição, citou o grito e o berro como não pertencentes ao exercício do comando pelas mulheres.

[...] até porque como em todo lugar, a mulher, por mais firme e dura que seja, ela tem uma capacidade agregante e de ouvir, e de ouvir diferente do homem. Isso faz parte da característica da mulher. Ela é agregadora, ela ouve, pode falar 'pra caramba', mas ela ouve, está acostumada a acolher. $E$ isso, às vezes, transforma a vida de quem está acostumado a levar grito e berro mais fácil (CF Wilma, 2016).

\footnotetext{
9 Esta expressão remete à série de desenho animado 'As meninas superpoderosas', veiculada na mídia televisiva. Essas meninas, que eram três, possuíam superpoderes, e os utilizavam para combater os vilões e, assim, salvar o mundo.
} 
Implicitamente, efetuou críticas a uma forma de autoridade exercida na $M B$ e, ainda que tenha essencializado os atributos do comando, demarcou outra abordagem. Ao dar continuidade à narrativa, utilizou o dado biológico para mostrar as limitações físicas da mulher, em comparação ao homem, e que ela pôde lançar mão dessas limitações e de capacidades inerentes para atingir seus objetivos.

Porque nós estamos em igual condição de capacidade intelectual, capacidade profissional, e capacidade de ser comandante, comandar, mesmo até na parte física, embora nós sejamos mais fracas, e que se pode treinar e se pode utilizar essa fragilidade para, talvez, até como uma arma de sucesso (CF Wilma, 2016).

As ponderações da CF Wilma trouxeram alguns elementos presentes nos debates produzidos pelos grupos feministas e de mulheres (Joana Maria PEDRO, 2005; PISCITELLI, 2004; Maria Luiza HEILBORN, 1999; 1996; Gayle RUBIN, 1993), tais como: a ideia de uma 'natureza feminina' e de uma 'natureza masculina', divergentes em sua essência; a compreensão do sujeito universal 'mulher' e do sujeito universal 'homem', possuidores de atributos em comum que as/os unificam; as características socialmente atribuídas ao masculino e ao feminino; as diferenças designadas e existentes entre homens e mulheres, concernentes ao aspecto físico/biológico e aquelas construídas no processo de socialização. Ademais, suas concepções reverberaram representações históricas e sociais do feminino e do masculino, embora o sentido enunciado não coloque a mulher em um patamar inferior ao do homem. Ao contrário, demarca sua compreensão das diferenças e valoriza as 'características da mulher' no cargo de comando.

No que diz respeito à CMG Vera, quando soube que foi escolhida para assumir a direção do SSPM, recorreu a autoridades da Marinha para compor a equipe de comando daquela OM. Em conversa com o Diretor de Ensino da Marinha, seu superior imediato, solicitou que a CF Tânia fosse indicada para ser vice-diretora, pois era uma militar de sua confiança. O pedido da CMG Vera foi atendido, demonstrando o reconhecimento dos seus superiores para aquela gestão. Além da confiança na CF Tânia, a indicação, possivelmente, esteve relacionada ao tipo de trabalho realizado no SSPM. A CF Tânia também era psicóloga e o SSPM é uma OM que concentra atividades específicas da área de psicologia, sendo a maior parte da tripulação composta por profissionais dessa área. Representou, ainda, a preocupação da CMG Vera, discutida anteriormente, de assegurar a titularidade de OM a outras/outros psicólogas/psicólogos, obtendo êxito, uma vez que a CF Tânia a sucedeu na direção.

Ela ressaltou que o SSPM foi a primeira OM cuja direção e a vice-direção foram ocupadas por mulheres. É importante destacar que no HNRe, na gestão da CF Wilma, não existia o cargo de vice-direção. Contudo, nessa OM, igualmente, ocorreu uma experiência pioneira de liderança formada por mulheres e diferenciada em termos de estrutura de comando do SSPM. Assim como a CF Wilma, a CMG Vera conheceu os desafios de construir uma gestão precursora e deu visibilidade às cobranças e expectativas institucionais pela condição de ser mulher.

Nós tivemos uma inspeção [...]. Vieram os Almirantes da área do pessoal fazer a inspeção na nossa OM. Todos vieram fazer a inspeção. Gostaram muito de tudo. Mas é aquele negócio... a gente tinha que ... não podia ter um ... nada, nem desse tamanho. Claro, porque todo mundo de olho. Vamos ver como é... duas mulheres juntas? Isso foi um desafio. Mas, tiramos de letra (CMG Vera, 2016 [grifo nosso]).

Outro ponto partilhado com a CF Wilma foi a dúvida da tripulação em relação à capacidade de duas mulheres gerirem uma OM. É, portanto, projetada a relação estabelecida entre sexo, competência técnica e cumprimento da missão.

Em relação à composição de sua gestão, a CMG Vera afirmou que não houve nenhum tipo de preconceito ou discriminação. Pontuou que as mulheres estavam há quase 30 anos na MB, por isso, a presença delas na Instituição estava consolidada. O paradoxo desta afirmação reside no não reconhecimento da dificuldade experienciada (FREITAS; LUZ, 2017), sinalizada anteriormente, ao ser alvo de insinuações a respeito de sua capacidade em dirigir uma OM com outra mulher. A CMG Vera não considerou tais atitudes como discriminatórias, assim como a CF Wilma.

A condução do seu comando foi marcada pelo diálogo com as/os subordinadas/ subordinados e pelo processo de escuta das suas necessidades, figurando, subliminarmente, como uma estratégia de gestão e controle. Desse modo, privilegiou a consolidação de relacionamentos interpessoais, inclusive para administrar os problemas de ordem operacional, além de pautar sua direção na liderança pelo exemplo, reforçando sua autoridade a partir de uma gestão relacional. Afirmou que em decorrência do seu conhecimento da $\mathrm{MB}$, da área administrativa e de psicologia, não precisou recorrer frequentemente a outras pessoas para auxiliála nos processos de tomada de decisão. Nestes momentos, quando necessário, buscava o apoio da vice-diretora.

Destacou que o conhecimento da rotina institucional e o fato de ser psicóloga contribuíram para o exercício do comando. Ela considerou que seu planejamento idealizado e executado 
para chegar à direção do SSPM foi necessário para a aquisição e o desenvolvimento de habilidades esperadas no exercício do cargo de direção.

[...] por isso que eu precisei, de repente, me preparar tanto. Me preparei para outras áreas além da técnica. E minha vida foi em uma área técnica. Me preparei tecnicamente, como psicóloga. Agora, essa parte toda administrativa, eu fui ganhando ao longo do tempo e fui me preparando para isso [...]. Então, eu acho que a minha maior característica é ... que foi, assim, uma parcela de planejar. Eu sou uma pessoa que gosta de planejar. Eu tenho um objetivo, eu vou planejar, e vou me esforçar, e fazer as coisas necessárias para chegar em um determinado ponto (CMG Vera, 2016).

As situações de preconceito nas gestões da CF Wilma e da CMG Vera, ainda que não denominadas, estiveram relacionadas ao fato de a equipe diretiva ter sido exclusivamente formada por mulheres. O pioneirismo das Oficiais, somado à ausência da figura masculina na gestão, representou um desafio a mais, o que potencializou as incertezas e inseguranças enfrentadas.

Para iniciar o relato da experiência da CMG Gelza, é importante esclarecer que o CMS é uma OM responsável pela manutenção de todos os equipamentos e sistemas de combate dos navios, como radares, sonares, sensores, rádios e softwares (CMG Gelza, 2016). Assim como o HNRe e o SSPM, o CMS destina-se à prestação de serviços, porém, dos meios operativos, propiciando, deste modo, o cumprimento da missão da MB, que corresponde ao monitoramento das fronteiras e sua defesa.

No tocante à sua gestão no CMS, a CMG Gelza utilizou três vezes o termo 'característica principal' para destacar suas atitudes no exercício da direção. Em cada menção ao termo, citou um atributo seu. O primeiro foi o 'ouvir mais as pessoas'.

Então, a minha característica principal, que eu desenvolvi mais aqui, foi ouvir mais as pessoas e tentar buscar soluções com amigos e companheiros de outras organizações para tentar resolver os problemas do CMS e para atender à missão deles (CMG Gelza, 2016).

Declarou que possuía tal qualidade antes de ser diretora, e que foi aprimorada quando iniciou seu comando, sendo esta necessária à prática de uma gestão relacional e democrática. Nas tomadas de decisão sempre consultava a opinião de outras pessoas para tirar dúvidas e apoiá-la nesse processo, recorrendo, inclusive, ao seu vice-diretor.

Outro atributo, associado ao primeiro, era 'tentar fazer justiça': “Então, a minha principal característica é tentar fazer justiça e não promover injustiça, para fazer tudo de acordo com a lei e com o que seja melhor [...]". Qualquer expressão de justiça e de igualdade se tornaria extremamente relevante no contexto em que a CMG Gelza estava inserida, uma vez que a estratificação institucional - de gênero e sexo -, com suas exclusividades, impossibilitava um tratamento igualitário de forma integral. Talvez, pela hierarquia institucional e por ser mulher, tenha se apropriado das marcas sociais designadas ao sujeito universal 'mulher' para propor, em seu comando, alternativas às assimetrias.

Por último, ressaltou seu dinamismo: "A minha principal característica é essa, é o dinamismo. Todo mundo sabe que eu gosto de ser dinâmica, eu não gosto de ver coisa parada, gosto de conversar com as pessoas, gosto de estar lá no chão de fábrica". A dinamicidade apontada era atinente à rotina do CMS, pois esta $\mathrm{OM}$ precisa responder com presteza às solicitações dos navios, uma vez que compõe a parte operativa da MB. Ademais, explicitou a proximidade que mantinha com as/os subordinadas/subordinados e o tipo de relação estabelecida. Do mesmo modo que as demais Oficiais, estabeleceu uma gestão baseada no relacionamento, sendo esta uma estratégia de proximidade com a tripulação, mas, igualmente, de poder.

Uma das conquistas relatadas pela CMG Gelza, como resultado de seu comando, foram as mudanças realizadas na OM que contribuíram para a qualidade de vida da tripulação.

As pessoas se sentem mais felizes hoje em dia do que se sentiam anos atrás. Isso é uma conquista maravilhosa, tá? Porque são pequenas coisas que nós vamos fazendo... Nós colocamos plantinhas no corredor, para quando as pessoas chegassem... não sei se você viu as plantinhas lá no corredor. A gente melhorou o tipo da comida. A primeira coisa que nós fizemos foi melhorar o cardápio, para colocar salada, para colocar menos gordura, menos fritura, menos doce, para a saúde das pessoas melhorarem. E ninguém morreu, ninguém teve infarto mais, não é? Antigamente tinha um ou dois infartos por ano, não é? (CMG Gelza, 2016).

A atenção dispensada ao bem-estar da tripulação, tornando o ambiente de trabalho mais agradável, com o uso das plantas e a adoção de uma alimentação saudável, esteve incorporada à sua concepção de gestão, logo, ao ato de cuidar, como próprio da condição feminina. $O$ cuidado com a saúde, alertado pela CMG Gelza, especialmente no que diz respeito à prevenção, é apresentado pela literatura como uma prática realizada pelas mulheres (Denise Machado Duran GUTIERREZ; Maria Cecília de Souza MINAYO, 2010; Maria Juracy Filgueiras TONELI; Marina Gomes Coelho de SOUZA; Rita de Cássia Flores MÜLLER, 2010; Romeu GOMES; Elaine Pereira do NASCIMENTO; Fábio Carvalho de ARAÚJO, 2007). 
Nesse sentido, as determinações históricas, sociais e biológicas são os principais argumentos para a definição da mulher como participante ativa das ações de prevenção à saúde, com centralidade para as construções de gênero: o corpo das mulheres pode originar uma vida; a necessidade periódica de realizar exames ginecológicos; a existência de serviços específicos de saúde para a mulher; elas cuidam de outras pessoas (filhas/filhos, mãe idosa/pai idoso, companheiro/esposo), por isso, também cuidam de si mesmas; não têm receio de mostrar sua vulnerabilidade; entre outras (TONELI; SOUZA; MÜLLER, 2010; GOMES; NASCIMENTO; ARAÚJO, 2007). A literatura também indica que as próprias mulheres pactuam, muitas vezes acriticamente, com sua responsabilização pelo cuidado.

Entretanto, o que a CMG Gelza evidenciou, para além da atenção ao campo da saúde e ao cuidado com o efetivo, foi a gestão dos comandos anteriores, formados unicamente por homens, que não apresentavam esses pontos de pauta. Suas decisões foram ampliadas e não se limitaram a responder à atividade técnica, mas abarcaram as relações interpessoais e o bem-estar.

As histórias das Oficiais titulares de OM apresentaram semelhanças e diferenças no que diz respeito ao acesso e ao exercício da direção. A liderança das entrevistadas evidenciou suas características, desenvolvidas ao longo de suas vidas e potencializadas (ou adquiridas) na prática do comando. A partir dos relatos, foi possível perceber um destaque às qualidades das sujeitas da pesquisa, necessárias a quem ocupa uma posição de poder, por exemplo, racionalidade, competência, autoridade e voz de comando (sinalizada em suas falas). Em um contexto de exercício do poder, tais qualidades são atribuídas, historicamente, ao homem/masculino. Por sua vez, outros predicados, requeridos a uma 'gestão relacional' e sensível às relações interpessoais, foram indicados em suas falas, como: proximidade com o efetivo; saber ouvir; buscar apoio; cuidado com o bem-estar da tripulação, entre outros, sendo estes socialmente designados à mulher/feminino. Outrossim, o trabalho desempenhado pelas Oficiais e as OM em que foram titulares faziam referência ao cuidado e às funções de apoio, embora a CMG Gelza tenha ocupado a direção de uma OM da área tecnológica, mais relacionada à missão precípua da MB.

O questionamento direto à conduta institucional em relação às mulheres não foi uma prática identificada nas narrativas das três entrevistadas. Logo, a problemática da realidade das mulheres/feminino na MB se restringiu à descrição do empírico. Os motivos para o compartilhamento de tal posição estão, provavelmente, relacionados à incorporação, em alguma medida, do ethos da Instituição e à pactuação com sua lógica e dinâmica, que se sobrepôs; aos objetivos políticos e profissionais voltados à carreira na MB; ao lugar de fala das Oficiais; e à ausência de uma participação política orientada pelas leituras feministas.

\section{Considerações finais}

As experiências das Oficiais titulares de OM, produzidas e reproduzidas no âmbito institucional, indicaram uma proximidade de vivências. O que as uniu esteve pautado pelo contexto institucional e social, bem como pelas apreensões correntes sobre o feminino e seu lugar na sociedade. As características que demarcaram seus comandos indicaram requisições de uma gestão situada em seu tempo. Todas - a seu modo - indicaram o exercício do controle e a competência como atributos marcantes em suas gestões, apesar dos desafios particulares enfrentados pela condição de serem mulheres e pioneiras nas funções exercidas. Apontaram, portanto, para as (des)construções de gênero sociais e institucionais e, paradoxalmente, explicitaram que a MB requisitou o ingresso e a ascensão das mulheres ao cargo de direção.

Suas narrativas projetaram situações de preconceito no cotidiano do comando, sem, contudo, serem explicitamente nomeadas como tal. Por isso, era imperioso que demonstrassem sua capacidade, sua superioridade, em comparação aos homens, apesar de não verbalizarem tal necessidade. A negação desses enfrentamentos pode estar relacionada à naturalização da condição feminina ou às estratégias de presença e ocupação dos espaços no âmbito da MB.

O progresso em suas carreiras esteve circunscrito a determinadas áreas da Marinha, embora suas experiências representassem conquistas feministas. Ao entrarem em uma instituição eminentemente masculina, integraram o conjunto de mulheres que não respondiam à figura tradicional da dona de casa e apontaram para a ocupação de outros lugares para além do espaço doméstico.

Suas trajetórias carecem de serem contadas e recontadas, ainda mais pelas chaves e 'olhares' dos estudos feministas e de gênero. É necessário também que as experiências das militares, como as descritas neste estudo, sejam partilhadas entre elas para que percebam as diferenças e as semelhanças que as conectam e, deste modo, possam iniciar outros processos de mudanças na MB. A identificação coletiva, como um 'sujeito político', ocorrerá a partir da apropriação das diversas expressões possíveis da mulher militar, assim como de um discurso e de uma prática política unificada.

\section{Referências}

ALBERTI, Verena. Manual de história oral. Rio de Janeiro: FGV, 2013. 
ALBERTI, Verena. Ouvir contar: textos em história oral. Rio de Janeiro: FGV, 2004.

ALMEIDA, Mariza Ribas D'Ávila de. Batalhas culturais de gênero: a dinâmica das relações de poder no campo militar naval. 2008. Dissertação (Mestrado) - Programa de Estudos Pós-Graduados em Política Social, Escola de Serviço Social da Universidade Federal Fluminense, Universidade Federal Fluminense, Rio de Janeiro, RJ, Brasil.

BOFF, Leonardo. "O cuidado essencial: princípio de um novo ethos". Inclusão Social, Brasília, v. 1, n. 1, p. 28-35, out./mar. 2005.

BOURDIEU, Pierre. Coisas ditas. São Paulo: Brasiliense, 2004.

BRASIL. Poder Naval (Comando da Marinha). Brasília: Action, 1997.

CARNEIRO, Sueli. "Enegrecer o Feminismo: a situação da mulher negra na América Latina a partir de uma perspectiva de gênero". Geledés: Instituto da Mulher Negra, São Paulo, 2011 . Disponível em https://www.geledes.org.br/enegrecer-o-feminismo-situacao-da-mulher-negra-na-americalatina-partir-de-uma-perspectiva-de-genero. Acesso em 04/10/2019.

CARREIRAS, Helena. "Diversidade social nas Forças Armadas: gênero e orientação sexual em perspectiva comparada". Nação e Defesa, Lisboa, n. 107 - 2a série, p. 61-68, primavera 2004.

CASTRO, Celso. O espírito militar: um antropólogo na caserna. Rio de Janeiro: Jorge Zahar, 2004.

CASTRO, Silvia Elaine Santos de. "Marcadores sociais da diferença: sobre as especificidades da mulher negra no Brasil”. In: XXIV SEMANA DE CIÊNCIAS SOCIAIS DA UEL. CIÊNCIAS SOCIAIS: DESAFIOS CONTEMPORÂNEOS, 24, 2013, Londrina, Universidade Estadual de Londrina. Anais... Londrina: Universidade Estadual de Londrina, 2013. p. 1-10.

COLLINS, Patricia Hill. "Se perdeu da tradução? Feminismo negro, interseccionalidade e política emancipatória". Parágrafo, São Paulo, v. 5, n. 1, p. 6-17, 2017. Disponível em http://revistaseletronicas. fiamfaam.br/index.php/recicofi/article/view/559/506. ISSN: 2317-4919. Acesso em 04/10/2019.

DELGADO, Lucília de Almeida Neves. História oral: memória, tempo, identidades. Belo Horizonte: Autêntica, 2010.

FONTENELE-MOURÃO, Tânia Maria. Mulheres no topo de carreira: flexibilidade e persistência. Brasília: Secretaria Especial de Políticas para as Mulheres, 2006.

FOUCAULT, Michel. "Michel Foucault, uma entrevista: sexo, poder e a política da identidade". Verve, São Paulo, n. 5, p. 260-277, 2004. Disponível em https://revistas.pucsp.br/verve/article/view/ 4995/3537. ISSN: 1676-9090. https://doi.org/10.23925/verve.v0i5.4995. Acesso em 04/20/2019.

FOUCAULT, Michel. "O sujeito e o poder". In: DREYFUS, Hubert L.; RABINOW, Paul (Orgs.). Michel Foucault: uma trajetória filosófica. Para além do estruturalismo e da hermenêutica. Rio de Janeiro: Forense Universitária, 2009. p. 231-249.

FREITAS, Lucas Bueno de; LUZ, Nanci Stancki da. "Gênero, ciência e tecnologia: estado da arte a partir de periódicos de gênero". Cadernos Pagu, Campinas, n. 49, el 74908, 2017. Disponível em http://www.scielo.br/pdf/cpa/n49/1 809-4449-cpa-18094449201 700490008.pdf. Epub 13/03/2017. ISSN 1809-4449. http://dx.doi.org/10.1590/1809444920170049 0008. Acesso em 04/10/2019.

GOMES, Romeu; NASCIMENTO, Elaine Ferreira do; ARAÚJO, Fábio Carvalho de. "Por que os homens buscam menos os serviços de saúde do que as mulheres? As explicações de homens com baixa escolaridade e homens com ensino superior". Cadernos de Saúde Pública, Rio de Janeiro, v. 23, n. 3, p. 565-574, mar. 2007.

GUTIERREZ, Denise Machado Duran; MINAYO, Maria Cecília de Souza. "Produção de conhecimento sobre cuidados da saúde no âmbito da família". Ciência \& Saúde Coletiva, Rio de Janeiro, v. 15, supl. 1, p. 1497-1508, jan./jun. 2010.

HARDING, Sandra. "¿Existe un método feminista?". In: BARTRA, Eli (Org.). Debates en torno a una metodología feminista. México: Universidad Autónoma Metropolitana - Unidad Xochimilco, 2002. p. 09-34.

HEILBORN, Maria Luiza. "Construção de si, gênero e sexualidade". In: HEILBORN, Maria Luiza (Org.). Sexualidade: o olhar das Ciências Sociais. Rio de Janeiro: Jorge Zahar, 1999. p. 40-58. 
HEILBORN, Maria Luiza. "Gênero, sexualidade e saúde". In: SILVA, Dayse de Paula Marques (Org.). Saúde, sexualidade e reprodução: compartilhando responsabilidades. Rio de Janeiro: EDUERJ, 1996. p. 101-110.

HITA, Maria Gabriela. "Igualdade, identidade e diferença(s): feminismo na reinvenção de sujeitos". In: ALMEIDA, Heloisa Buarque de; COSTA, Rosely Gomes; RAMÍREZ, Martha Celia; SOUZA, Érica Renata de (Orgs.). Gênero em matizes. Bragança Paulista: CDAPH, 2002. p. 319-351.

JÚNIOR, Hermógenes Hiron Marques. O corpo auxiliar feminino da reserva da Marinha. 1982. Especialização (Curso de Comando e Estado-Maior do Exército) - Escola de Comando e EstadoMaior do Exército, Rio de Janeiro, RJ, Brasil.

LOMBARDI, Maria Rosa. "Profissão: oficial engenheira naval da Marinha de Guerra do Brasil". Revista Estudos Feministas, Florianópolis, v. 18, n. 2, p. 529-546, 2010. Disponível em http:// www.scielo.br/scielo.php?pid=S0104-026X2010000200014\&script= sci_abstract\&tIng =pt. ISSN 0104-026X. http://dx.doi.org/10.1590/S0104-026X20100002 00014. Acesso em 04/10/2019.

LOMBARDI, Maria Rosa; BRUSCHINI, Cristina; MERCADO, Cristiano M. As mulheres nas Forças Armadas brasileiras: a Marinha do Brasil. 1980-2008. São Paulo: FCC/DPE, 2009.

MORAES, Marcia. Ser humana: quando a mulher está em discussão. Rio de Janeiro: DP\&A, 2002.

NICHOLSON, Linda. "Interpretando o gênero". Revista Estudos Feministas, Florianópolis, v. 8, n. 2, p. 09-41, jul./dez. 2000.

NOGUEIRA, Maria da Conceição de Oliveira Carvalho. "Os discursos das mulheres em posições de poder". Cadernos de Psicologia Social do Trabalho, São Paulo, v. 9, n. 2, p. 57-72, 2006. Disponível em http://www.revistas.usp.br/cpst/article/view/25965/27696. ISSN 1981-0490. https://doi.org/ 10.11606/issn. 1981-0490.v9i2p57-72. Acesso em 04/10/2019.

PEDRO, Joana Maria. "Traduzindo o debate: o uso da categoria gênero na pesquisa histórica". História, São Paulo, v. 24, n. 1, p. 77-98, 2005.

PISCITELLI, Adriana. "Reflexões em torno do gênero e feminismo". In: COSTA, Claudia de Lima; SCHMIDT, Simone Pereira (Orgs.). Poéticas e políticas feministas. Florianópolis: Mulheres, 2004. p. 43-66.

PORTELLI, Alessandro. "Tentando aprender um pouquinho: algumas reflexões sobre a ética na história oral”. Projeto História, São Paulo, n. 15, p. 13-49, abr. 1997.

RAGO, Margareth. "Epistemologia feminista, gênero e história". In: PEDRO, Joana Maria; GROSSI, Miriam Pillar (Orgs.). Masculino, feminino, plural: gênero na interdisciplinaridade. Florianópolis: Mulheres, 1998. p. 21-41.

RIBEIRO, Djamila. "Feminismo Negro para um novo marco civilizatório: uma perspectiva brasileira". SUR: Revista Internacional de Direitos Humanos, São Paulo, v. 13, n. 24, p. 99-104, 2016. Disponível em https://sur.conectas.org/wp-content/uploads/2017/02/9-sur-24-por-djamila-ribeiro.pdf. ISSN 19833342. Acesso em 04/10/2019.

RIBEIRO, Djamila. O que é lugar de fala? Belo Horizonte: Letramento, 2017.

ROHDEN, Fabíola. Uma ciência da diferença: sexo e gênero na medicina da mulher. Rio de Janeiro: Fiocruz, 2001.

RUBIN, Gayle. O tráfico de mulheres: notas sobre a "economia política" do sexo. Recife: SOS Corpo, 1993.

SALGADO, Martha Patricia Castañeda. Metodología de la investigación feminista. Cidade do México: Centro de Investigaciones Interdisciplinarias en Ciencias y Humanidades, Universidad Nacional Autónoma de México, 2008.

SALVATICI, Silvia. "Memórias de gênero: reflexões sobre a história oral de mulheres". História Oral, Rio de Janeiro, v. 8, n. 1, p. 29-42, jan./jun. 2005.

SCOTT, Joan Wallach. "A invisibilidade da experiência". Projeto História, São Paulo, v. 16, p. 297325, jan./jun. 1998. 
TONELI, Maria Juracy Filgueiras; SOUZA, Marina Gomes Coelho de; MÜLLER, Rita de Cássia Flores. "Masculinidades e práticas de saúde: retratos da experiência de pesquisa em Florianópolis/SC". Physis: Revista de Saúde Coletiva, Rio de Janeiro, v. 20, n. 3, p. 973-994, 2010.

Vanessa Coelho dos Reis (vanessa.reis@ifc.edu.br) é mestra em Serviço Social pela Universidade Federal de Santa Catarina e graduada em Serviço Social pela Universidade Federal do Rio de Janeiro. Assistente Social do Instituto Federal Catarinense - Campus Brusque.

Luciana Patrícia Zucco (Ipzucco@uol.com.br) possui Doutorado pelo Instituto Fernandes Figueira/Fiocruz (2007) e Mestrado em Serviço Social pela PUC-Rio (1997). Foi Professora Adjunta da Escola de Serviço Social/UFRJ (1997-2011). Atualmente, é Professora Associada do Departamento de Serviço Social/UFSC. Professora do PPGSS/CSE/UFSC e do PPGICH/CFH/UFSC; coordenadora do NUSSERGE/DSS/CSE/UFSC, integrante do Instituto de Gênero (IEG/UFSC).

\section{COMO CITAR ESSE ARTIGO DE ACORDO COM AS NORMAS DA REVISTA}

REIS, Vanessa Coelho dos; ZUCCO, Luciana Patrícia. "As experiências das Oficiais da Marinha do Brasil no exercício do comando". Revista Estudos Feministas, Florianópolis, v. 28, n. 3, e61934, 2020.

\section{CONTRIBUIÇÃO DE AUTORIA}

Vanessa Coelho dos Reis: concepção, coleta de dados e análise de dados, elaboração do manuscrito, redação, discussão de resultados.

Luciana Patrícia Zucco: concepção, análise de dados, elaboração do manuscrito, redação, discussão de resultados.

\section{FINANCIAMENTO}

Não se aplica.

CONSENTIMENTO DE USO DE IMAGEM

Não se aplica.

APROVAÇÃO DE COMITÊ DE ÉTICA EM PESQUISA

Não se aplica.

\section{CONFLITO DE INTERESSES}

Não se aplica.

\section{LICENÇA DE USO}

Este artigo está licenciado sob a Licença Creative Commons CC-BY International. Com essa licença você pode compartilhar, adaptar, criar para qualquer fim, desde que atribua a autoria da obra.

\section{HISTÓRICO}

Recebido em 10/03/2019

Reapresentado em 07/10/2019

Reapresentado em 30/12/2019

Aprovado em 24/01/2020 